\title{
Exenatide once weekly: clinical outcomes and patient satisfaction
}

\author{
This article was published in the following Dove Press journal: \\ Patient Preference and Adherence \\ 17 August 2010 \\ Number of times this article has been viewed
}

Biju Jose'

Abd A Tahrani ${ }^{1,2}$

Milan K Piya ${ }^{1,2}$

Anthony H Barnett ${ }^{1,2}$

'Department of Diabetes and Endocrinology, Heart of England NHS Foundation Trust, Birmingham, UK;

${ }^{2}$ School of Clinical and Experimental Medicine, University of Birmingham,

Birmingham, UK
Correspondence:Abd A Tahrani The MIDRU, Birmingham Heartlands Hospital, Birmingham B9 5SS, UK $\mathrm{Tel}+44$ 780I549960

Email a.a.tahrani@bham.ac.uk
Background: Type 2 diabetes mellitus (T2DM) is a complex disorder in which interactions between environmental and genetic factors result in the development of insulin resistance (in most cases) and progressive pancreatic $\beta$-cell failure. The currently available oral anti-diabetes treatments are effective as monotherapy; however, due to the progressive decline in $\beta$-cell function, most patients will require the use of combination therapy and eventually insulin to reach glycemic targets. These therapeutic options are not without undesirable side effects such as weight gain and hypoglycemia. Furthermore, T2DM is associated with impaired quality of life (QOL) and poor compliance with treatment. Hence, there is a need for anti-diabetes agents that result in sustained improvements in glycemic control without hypoglycemia or weight gain and have a positive impact on patients QOL and thereby hopefully improve compliance. Incretin-based therapy is the latest addition to anti-diabetes treatments which addresses some of the shortcomings of older treatments.

Aims: To review the evidence for the use of exenatide once-weekly.

Methods: We have searched Medline using the terms "exenatide", "exenatide once-weekly", and "exenatide LA".

Results: Exenatide once-weekly is an incretin mimetic that is currently undergoing phase 3 clinical trials, and has been shown to improve glycemic parameters $\left(\mathrm{HbA}_{1 \mathrm{c}}\right.$ and fasting and postprandial glucose levels), with low risk of hypoglycemia, causes weight loss, and use was associated with improvements in patient satisfaction which might have a positive impact on treatment compliance.

Conclusions: Exenatide once-weekly is effective, well tolerated in patients with T2DM and should be a useful addition to the available range of anti-diabetes treatments.

Keywords: diabetes mellitus, incretins, exenatide once-weekly, quality of life, treatment satisfaction

\section{Introduction}

Type 2 diabetes mellitus (T2DM) is a global epidemic with an estimated worldwide prevalence of $6 \%$ (246 million people) in 2007 that is forecasted to rise to $7.3 \%$ (380 million) by $2025 .^{1,2}$ The health, social, and economic burden of T2DM is great; ${ }^{3-5}$ it continues to pose a major challenge to healthcare provision around the world.

The development of insulin resistance (IR) and pancreatic $\beta$-cell dysfunction due to various environmental and genetic factors results in onset of T2DM. ${ }^{6,7}$ Despite obesity being the single most important contributor to IR, most obese insulin-resistant individuals do not develop T2DM ${ }^{8,9}$ because their $\beta$-cells are capable of producing sufficient insulin to maintain euglycemia. ${ }^{9-13}$ This suggests that the failure of $\beta$-cells to secrete sufficient insulin to overcome IR is the key step in the development and progression 
of T2DM. ${ }^{6,7,9,10}$ Pancreatic $\alpha$-cell dysfunction manifesting as non-suppressed glucagon secretion in the presence of hyperglycemia is also manifest in patients with T2DM. ${ }^{14}$

Several pharmacological agents have been developed to treat patients with T2DM. They either improve insulin resistance (biguanides, glitazones), stimulate insulin secretion from the $\beta$-cell (sulfonylureas, metaglinides), or decrease glucose absorption from the gut ( $\alpha$-glucosidase inhibitors). ${ }^{15}$ The initial improvements in glycemic control observed with these agents as monotherapy are not sustained because of the progressive nature of the disease due to the continuing decline in $\beta$-cell function. ${ }^{9}{ }^{16}$ This often necessitates the use of combination therapy and eventually insulin. Furthermore, current agents may be associated with undesirable side effects including gastrointestinal (metformin, $\alpha$-glucosidase inhibitors), weight gain (sulfonylureas, metaglinides, glitazones, and insulin), and hypoglycemia (sulfonylureas, metaglinides, and insulin). ${ }^{17}$ These side effects may contribute to further worsen the already impaired health-related quality of life (QOL) found in patients with T2DM ${ }^{18}$ and may contribute to poor compliance common in this group of patients. ${ }^{19}$

Treatment acceptability and adherence are particularly important in the management of T2DM. A systematic review showed that many patients took less than their prescribed dose of insulin and/or oral anti-diabetes medications ${ }^{20}$ and that a substantial proportion of patients had difficulty in dealing with various elements of the chronic disease management, particularly adhering to a strict drug regimen. ${ }^{21,22}$

Taking the above into account, there is a need for new pharmacological agents that are well tolerated with sustainable impact on glycemic control, and with very low risk of hypoglycemia, cause weight loss (or at least no weight gain) and thereby encourage patient adherence to therapy. Incretinbased therapy is the latest class of anti-diabetes medications to become available and addresses some of the shortcomings of conventional anti-diabetes treatments. Incretin-based therapy can be given either orally (dipeptidyl peptidase-4 (DPP-4) inhibitors) or via a subcutaneous injection (glucagon-like peptide (GLP-1) analogues/mimetics). They improve glycemic control with favorable impact on weight and low risk of hypoglycemia (apart from when used with sulfonylureas). ${ }^{23}$ In addition, animal studies have shown that some of these agents improve $\beta$-cell survival, ${ }^{23}$ which if true in humans might result in a more sustained impact on glycemic control. GLP-1 analogs/mimetics are given in once- or twice-daily dosing regimes. However, other drugs are in development in this category that require administration once weekly or even less frequently. ${ }^{23}$ Such a dosing regimen might be highly acceptable to patients and encourage compliance with treatment.

In this article, we aim to review the available data regarding the once-weekly use of exenatide in the management of T2DM and the potential patient considerations for the use of this drug. Further details regarding incretin-based therapies are not within the scope of this article and can be found elsewhere. $^{24-27}$

\section{Incretins}

Incretins are hormones that are released from the gut in response to ingestion of food. ${ }^{28}$ The incretin effect was first described in 1964, when it was observed that the insulin response to oral glucose challenge was substantially higher than to an intravenous glucose load. ${ }^{29}$ The incretin response accounts for at least $50 \%$ of insulin secretion in healthy individuals. ${ }^{30}$

Glucose-dependent insulinotropic polypeptide (GIP) was the first incretin to be isolated and characterized. ${ }^{31,32}$ It is a 42 amino acid peptide secreted in the bioactive form from the K-cells in duodenum and jejunum in response to ingestion of carbohydrates and lipids. ${ }^{33}$ The second incretin to be isolated was GLP-1, which is cleaved from pro-glucagon and secreted from the L-cells in the distal ileum and colon. ${ }^{33}$ GLP-1 levels are reduced in patients with T2DM, unlike GIP levels which are maintained. ${ }^{34}$

Both GIP and GLP-1 facilitate glucose-dependent insulin secretion through their action on pancreatic $\beta$-cells. GLP-1 increases insulin gene transcription as well as all the steps of insulin biosynthesis. ${ }^{35}$ In addition, GLP-1 results in glucosedependent glucagon suppression, delays gastric emptying, increases satiety, and possibly reduces insulin resistance. ${ }^{36,37}$ There is also evidence that GLP-1 increases $\beta$-cell mass in animal studies. ${ }^{38}$

GLP-1 secretion is reduced in patients with T2DM. ${ }^{39}$ Although there is a blunting of GLP-1 secretory response in these patients, their response to exogenous GLP-1 is intact. ${ }^{23}$ A continuous 6-hour intravenous infusion of GLP-1 in the fasting state, leading to GLP-1 levels 2-3 times higher than normally seen after meals, resulted in lowering of glucose and glucagon levels, with increases in insulin secretion without any hypoglycemic events in patients with poorly controlled T2DM. ${ }^{40}$ Subcutaneous GLP-1 was also shown to have a similar glucose-lowering effect when administered pre-meal in patients with T2DM. ${ }^{41}$

Incretins are rapidly metabolized by the enzyme DPP-4, and thus have extremely short half-lives (GIP $<2$ minutes and GLP-1 5-7 minutes). ${ }^{42,43}$ The short half-life of these naturally occurring incretins limited their clinical use. This led 
to the development of various modifications of the amino acids of GLP-1, rendering them DPP-4 resistant. Exenatide (Byetta ${ }^{\circledR}$; Eli Lilly), a synthetic analog of exendin-4, was the first-in-class incretin mimetic. Liraglutide (Victoza ${ }^{\circledR}$; Novo Nordisk), an analog of human GLP-1, is a fatty acid derivative of GLP-1 that has been approved for clinical use more recently. There are several long-acting once-weekly preparations currently in phase 3 clinical trials - exenatide onceweekly (Byetta ${ }^{\circledR}$; Eli Lilly), albiglutide (GlaxoSmithKline) and taspoglutide (Ipsen and Roche), all of which show promising results. Research has also targeted developing inhibitors of the DPP-4 enzyme. The currently available DPP-4 inhibitors are sitagliptin (Januvia ${ }^{\circledR}$; Merck \& Co), vildagliptin (Galvus ${ }^{\circledR}$; Novartis) and saxagliptin (Onglyza ${ }^{\circledR}$; Bristol-Myers Squibb and Astra-Zeneca). Alogliptin (Takeda) and linagliptin (Ondero ${ }^{\circledR}$; Boehringer Ingelheim) are currently undergoing phase 3 clinical trials.

Exenatide, a synthetic version of the naturally occurring salivary peptide isolated from the Gila monster (Heloderma suspectum), is a partial structural analog of human GLP-1 and has 53\% amino acid sequence homology with human GLP- $1 .{ }^{44}$ It contains a glycine at position 2 , in contrast to human GLP-1, which has an alanine at position 2, thus making the molecule DPP-4 resistant, in turn conferring a longer half-life. ${ }^{44}$ Exenatide has a half-life of 3.3-4.0 hours and clinical effects lasting for up to 8 hours. ${ }^{45-47}$ Exenatide treatment results in significant reductions in fasting plasma glucose (FPG) and post-prandial glucose (PPG) in patients with T2DM. ${ }^{48-51}$ In addition, it results in slowing of gastric emptying (which contributes to the reductions in PPG), ${ }^{52}$ appetite suppression ${ }^{53}$ and weight loss. ${ }^{54}$

The AC2993 Diabetes Management for Improving Glucose Outcomes (AMIGO) trials were three 30-week randomized, triple-blind, placebo-controlled, multicenter trials that had similar design and examined the impact of exenatide treatment on glycemic control in patients with T2DM. ${ }^{48,55,56}$ They enrolled subjects aged 16-75 years who were poorly controlled on metformin and/or sulfonylurea with $\mathrm{HbA}_{1 \mathrm{c}} 7.5 \%-11 \%$. In the AMIGO trials, patients were randomized to placebo, exenatide $5 \mu \mathrm{g}$ or exenatide $10 \mu \mathrm{g}$ while continuing metformin and/or sulfonylurea. By week 30, exenatide $10 \mu \mathrm{g}$ resulted in mean $\mathrm{HbA}_{1 \mathrm{c}}$ reduction of $-0.8 \% \pm 0.1 \%$ to $-0.9 \pm 0.1 \%$ compared with a $-0.16 \% \pm 0.1 \%$ to $0.08 \% \pm 0.1 \%$ in placebo. ${ }^{55}$ The effects of exenatide on glycemic control appeared to be sustainable as reductions achieved at 30 weeks $(-1.0 \% \pm 0.1 \%)$ were maintained at 82 weeks $^{57}$ and 3 years $^{58}$ in the open-label extensions of the AMIGO trials.
The open-label extensions of the AMIGO trial also showed that exenatide treatment promotes progressive weight loss up to 82 weeks $(-2.1 \pm 0.3 \mathrm{~kg}$ versus $-4.0 \pm 0.3 \mathrm{~kg}$ for exenatide $10 \mu \mathrm{g}$ week 30 versus week 82 respectively). ${ }^{57,59}$ Furthermore, a subset of patients who had 3.5 years of exenatide exposure had reductions in triglycerides of $12 \%$ $(P=0.0003)$; LDL-C decreased by $6 \%$ ( $P<0.0001)$, and HDL-C increased by $24 \%(P<0.0001) .{ }^{59}$

Exenatide is generally well tolerated long term, but the most commonly reported adverse events (AEs) (mostly in the first few weeks of treatment) are nausea, vomiting, diarrhea, headache, dizziness, and dyspepsia. ${ }^{60}$ In a recent metaanalysis, exenatide was associated with a significant increase in the proportion of patients experiencing hypoglycemia in placebo-controlled trials (OR: $2.92(1.49-5.75), P=0.002)$. This excess, however, was only observed when exenatide was combined with sulfonylureas. ${ }^{61}$ Concerns about acute pancreatitis have been raised in patients using exenatide. However, a 1-year follow-up study of patients who were initiated on exenatide, sitagliptin, glyburide, or metformin showed the risk of acute pancreatitis to be comparable between the cohorts. ${ }^{62}$ Nonetheless, the FDA has changed the labeling on the drug to warn about possibility of acute pancreatitis particularly in susceptible patients, based on post-marketing analysis showing 30 reported cases of pancreatitis in 2007 and 6 cases of necrotizing hemorrhagic pancreatitis in $2008 .{ }^{60}$ The FDA also warns that exenatide should not be used in patients with severe renal impairment (creatinine clearance $<30 \mathrm{~mL} / \mathrm{min}$ ) or end-stage renal failure, and should be used with caution in those with renal transplant or moderate renal impairment (creatinine clearance $30-50 \mathrm{~mL} / \mathrm{min}$ ). ${ }^{60}$

Although exenatide is relatively well tolerated and effective in improving glycemic control with favorable impact on weight and low risk of hypoglycemia, the main drawback is that it needs to be administered by twice-daily injections. As a result, the development of exenatide once-weekly is now in progress.

\section{Exenatide once-weekly Chemistry}

Exenatide once-weekly uses a sustained release drug delivery system. Molecules of exenatide are encapsulated in injectable microspheres of poly (D, L lactic-co-glycolic acid), a biodegradable polymeric matrix commonly used in extended release preparations. ${ }^{63}$ This poly-lactide-glycolide and exenatide microsphere suspension allows gradual drug delivery at a controlled rate by diffusion and erosion of the microspheres. ${ }^{63,64}$ 


\section{Pharmacokinetics}

Mean plasma concentration of exenatide once-weekly $(0.8$ or $2 \mathrm{mg}$ ) reached clinically significant levels (at which exenatide lowers blood glucose) by week 2 in a 15-week phase 2 study of 45 adults (60\% men, 60\% Caucasians) whom glycemic control was suboptimal $\left(\mathrm{HbA}_{1 \mathrm{c}} 8.5 \% \pm 1.2 \%\right)$ with metformin and/or life-style changes. ${ }^{64,65}$ By week 6 , exenatide onceweekly attained a maximum concentration higher than that attained by a single injection of exenatide $10 \mu \mathrm{g}$ (a steady state concentration of $232 \mathrm{pg} / \mathrm{mL}$ versus $211 \mathrm{pg} / \mathrm{mL}) .{ }^{59}$ Six weeks after stopping treatment, the serum concentration of exenatide once-weekly declined steadily to insignificant levels. ${ }^{64}$

In a randomized, double-blind, parallel study in Japanese patients with T2DM (59\% men, aged $58 \pm 9$ years), the AUC (0-8 hours) of exenatide once-weekly on day 1 was 187.6 (133.7-263.3) pg* $\mathrm{h} / \mathrm{mL}$ and 405.6 (278.4-590.8) $\mathrm{pg} * \mathrm{~h} / \mathrm{mL}$ for $0.8 \mathrm{mg}$ and $2 \mathrm{mg}$ respectively. ${ }^{66}$ The Cmax on day 1 was $64.3(38.3-107.8) \mathrm{pg} / \mathrm{mL}$ for $0.8 \mathrm{mg}$ and 137.3 (74.6-252.6) $\mathrm{pg} / \mathrm{mL}$ for $2 \mathrm{mg}$ of exenatide once-weekly. Geometric mean $(90 \% \mathrm{CI})$ steady-state plasma concentrations were 81.2 (68.3-96.4) pg/mL and 344.5 (256.5-462.7) pg/mL with $0.8 \mathrm{mg}$ and $2.0 \mathrm{mg}$ respectively (Figure 1 ). ${ }^{66}$

The diabetes therapy utilization researching changes in $A_{1 c}$, weight, and other factors through intervention with Exenatide once-weekly (DURATION)-1 study (described below) showed that plateau concentrations of exenatide were achieved after 6-10 weeks of exenatide once-weekly with a geometric mean steady state plasma concentration of $71.7 \mathrm{pmol} / \mathrm{L}{ }^{67}$

\section{Clinical efficacy}

\section{Impact on glycemic parameters}

There are 3 published randomized controlled trials that assessed the impact of exenatide once-weekly on glycemic parameters (Table 1). Exenatide once-weekly produced significant reductions in $\mathrm{HbA}_{1 \mathrm{c}}$, FPG, and PPG when used in drug-naïve patients or patients treated with one or more oral anti-diabetes therapy. ${ }^{64,66,67}$

The DURATION-1 study was a randomized, open-label, non-inferiority study that compared exenatide $2.0 \mathrm{mg}$ weekly to exenatide $10 \mu \mathrm{g}$ twice daily in patients with T2DM. 303 patients were enrolled and 295 (53\% men, 78\% Caucasians) were randomized. ${ }^{67}$ All patients underwent a 3-day lead-in period with exenatide $5 \mu \mathrm{g}$ twice daily, after which they were randomized to either exenatide $2.0 \mathrm{mg}$ onceweekly or exenatide $5 \mu \mathrm{g}$ twice daily for 28 days, followed by exenatide $10 \mu \mathrm{g}$ twice daily. Participants had a mean age of $55 \pm 10$ years with a mean BMI of $35 \pm 5 \mathrm{~kg} / \mathrm{m}^{2}$. The baseline anti-diabetes treatment included metformin (73\%), sulfonylurea (37\%), and thiazolidinediones (16\%) alone or in combination. ${ }^{67}$ By week 10 , there were significantly greater reductions in $\mathrm{HbA}_{1 \mathrm{c}}$ in the once-weekly group compared

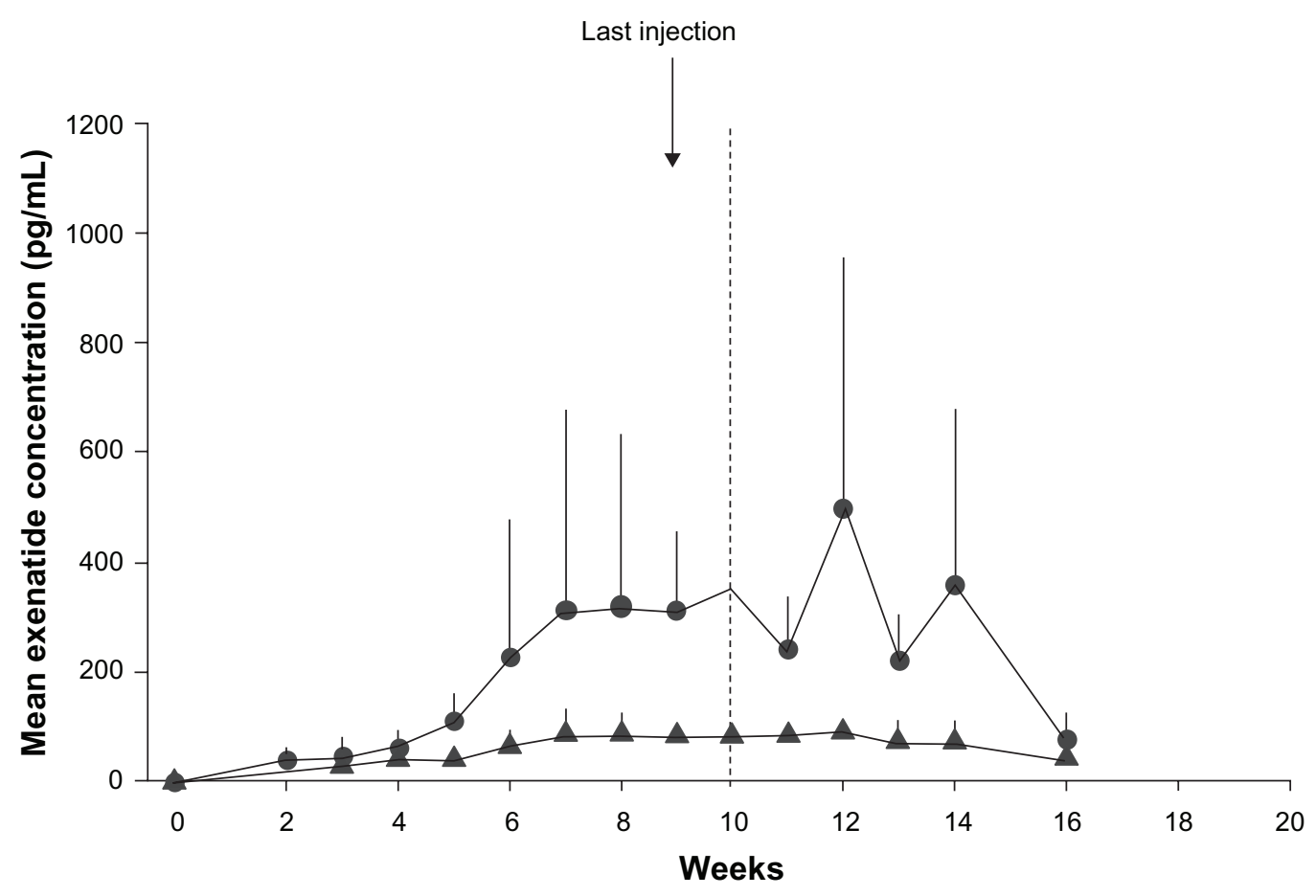

Figure I Mean $( \pm S D)$ plasma exenatide trough concentration-versus-time profiles in pharmacokinetic evaluable patients receiving exenatide once weekly 0.8 mg (closed triangles) $(\mathrm{n}=8)$ or exenatide once weekly $2.0 \mathrm{mg}$ (closed circles) $(\mathrm{n}=6)$. Reproduced with permission from Iwomoto K, et al. Endocr J. 2009;56(8):95I-962.66 


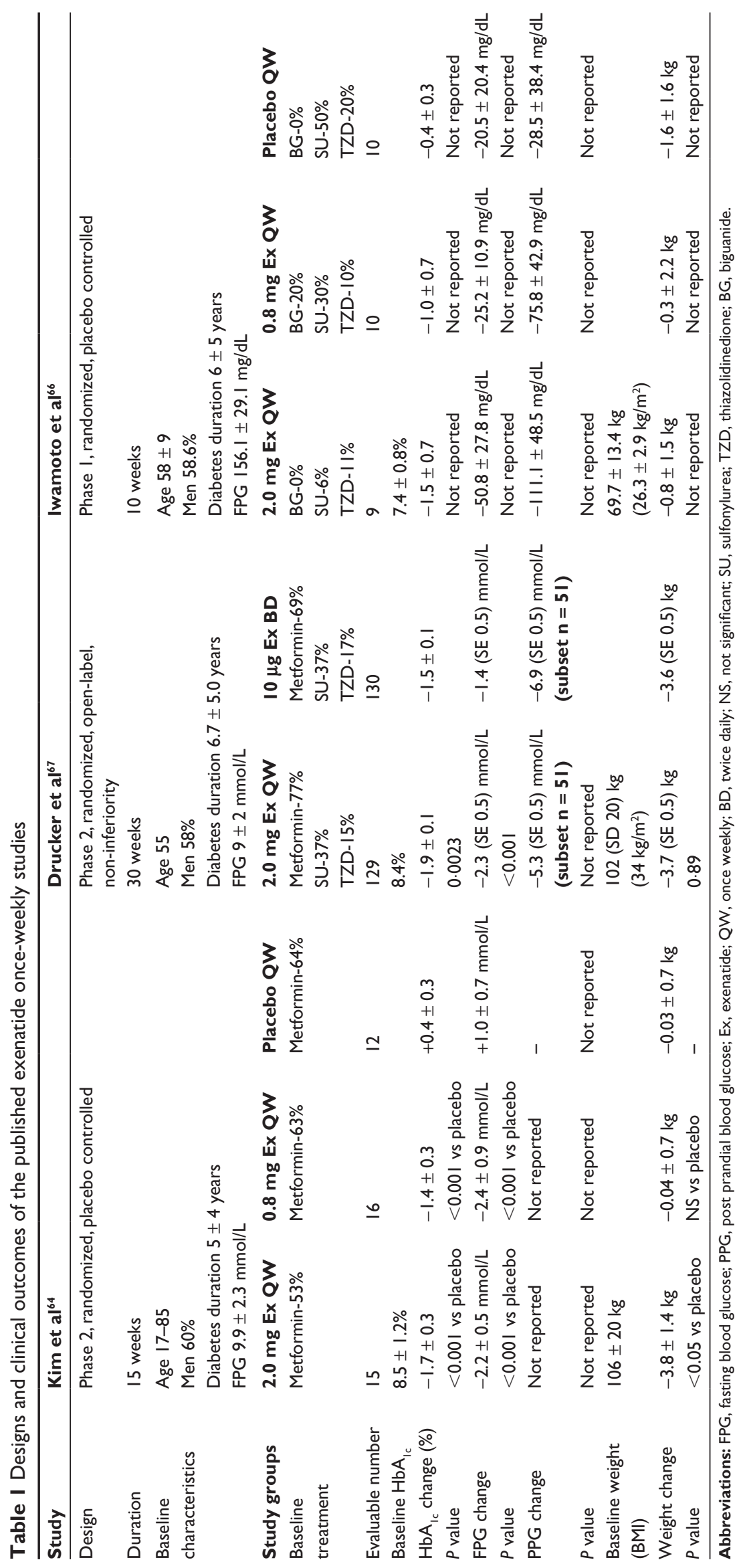


with the twice-daily group, which continued to be the case until study end (week 30) (Table1). A greater proportion of patients randomized to exenatide once-weekly achieved target $\mathrm{HbA}_{1 \mathrm{c}} \leq 7.0 \%$ (77\% versus $\left.61 \% ; P=0.0039\right)$. Exenatide once-weekly also resulted in greater reductions of FPG and 2-hour PPG (measured during a mixed meal tolerance test) (Table 1). ${ }^{67}$

In another randomized, placebo-controlled, phase 2 trial, 45 (60\% male) drug-naïve or metformin-treated patients with T2DM were randomized to $2.0 \mathrm{mg}$ or $0.8 \mathrm{mg}$ exenatide onceweekly or placebo. ${ }^{64} \mathrm{HbA}_{1 \mathrm{c}}$ reductions were apparent in both the exenatide once-weekly groups from week 3 onwards and continued to improve until study end (Table 1). $86 \%$ of the $2.0 \mathrm{mg}$ group and $36 \%$ of the $0.8 \mathrm{mg}$ group achieved target $\mathrm{HbA}_{1 \mathrm{c}} 7.0 \%$ or less compared with $0 \%$ in the placebo group. ${ }^{64}$ In addition, by week 15 , exenatide once-weekly (2.0 $\mathrm{mg}$ or $0.8 \mathrm{mg}$ ) resulted in significant reductions in FPG and PPG (based on self monitored blood glucose profiles) compared with placebo.

Exenatide once-weekly was also examined in a Japanese population in a 10 -week randomized, placebo-controlled, double-blind, parallel study in patients with T2DM suboptimally controlled by life style and/or biguanide, sulfonylurea, thiazolidinedione, or combinations of these agents. ${ }^{66}$ Patients continued their baseline medications during this study. Patients were randomized in a $1: 1: 1$ ratio to subcutaneous placebo once weekly, exenatide once weekly $0.8 \mathrm{mg}$, or exenatide once weekly $2.0 \mathrm{mg}$. ${ }^{66}$ At week 10 , there was significant reduction in $\mathrm{HbA}_{1 \mathrm{c}}$ in the exenatide onceweekly groups compared with placebo (Table 1). Similarly, FPG and PPG concentrations showed clinically relevant reductions in the exenatide once-weekly groups compared with placebo (Table 1).

The impact of exenatide once weekly seems to be sustainable up to 2 years following initiating treatment. ${ }^{68,69}$ In the open-label extension of the DURATION-1 trial, 258 patients entered the 22-week open-ended assessment phase $(n=128$ exenatide once weekly only; $n=130$ switched from daily to once weekly exenatide). ${ }^{68}$ Exenatide once weekly maintained the $\mathrm{HbA}_{1 \mathrm{c}}$ improvements through the 52 weeks $(-2.0 \%[-2.1 \%$ to $-1.8 \%])$. Patients switching from daily to weekly exenatide achieved further $\mathrm{HbA}_{1 \mathrm{c}}$ improvements, but both groups had a mean $\mathrm{HbA}_{1 \mathrm{c}}$ of $6.6 \%$ at study-end. At week $52,71 \%$ and $54 \%$ of all patients achieved an $\mathrm{A}_{1 \mathrm{c}}<7.0 \%$ and $\leq 6.5 \%$, respectively. ${ }^{68}$ This glycemic improvement was achieved without any major hypoglycemia. A further open-label extension of the DURATION-1 trial involving 135 patients who have completed 2 years treatment with
$2 \mathrm{mg}$ exenatide once weekly showed that the initial improvements in $\mathrm{HbA}_{1 \mathrm{c}}$ were maintained at 2 years with $66 \%$ and $42 \%$ of patients achieving an $\mathrm{HbA}_{1 \mathrm{c}} \leq 7.0 \%$ and $\leq 6.5 \%$, respectively. ${ }^{69}$

\section{Impact on weight}

Similar to exenatide twice-daily treatment, exenatide once weekly results in significant weight loss (Table 1). In the study by Kim et al exenatide once weekly $2 \mathrm{mg}$ resulted in a weight loss of $3.8 \pm 1.4 \mathrm{~kg}$ (mean $\pm \mathrm{SE}$ ) from baseline by week 15 ( $P<0.05$, compared with the placebo) ${ }^{64}$ In the DURATION-1 trial, the weekly exenatide treatment group had a weight change of $-3.7 \mathrm{~kg}$ (SE 0.5) at week 30, which was comparable to the twice-daily exenatide treatment $\left(-3.6 \mathrm{~kg}\right.$ [SE 0.5]). ${ }^{67}$

However, in the Japanese study, exenatide once weekly resulted in a weight neutral effect, while the placebo group lost $1.6 \mathrm{~kg}$ (Table 1). ${ }^{66}$ This effect was seen in earlier exenatide twice daily studies in Japanese subjects. ${ }^{70}$ The authors hypothesize that the leanness of the Japanese cohort could contribute to this apparent neutral effect on weight.

The impact of exenatide once weekly on weight seems to be sustainable. At 52 weeks, body weight was reduced by $>4 \mathrm{~kg} .{ }^{68}$ In the 2 -year open-label extension of the DURATION-1 study, there was significant reduction in body weight from baseline $(-3.6 \pm 0.6 \mathrm{~kg} ; 95 \% \mathrm{CI}:-4.8$ to $-2.3 \mathrm{~kg}$ ) by 2 years. ${ }^{69}$

\section{Impact on cardiovascular risk factors}

Exenatide once weekly resulted in significant reductions in lipids and blood pressure (Table 2). ${ }^{67}$

The 2-year open-label extension of the DURATION-1 study reported that exenatide once weekly improved serum lipids (triglycerides: $-18 \%, 95 \%$ CI $-24 \%$ to $-12 \%$; total cholesterol: $-0.25 \pm 0.09 \mathrm{mmol} / \mathrm{L}, 95 \% \mathrm{CI}$ -0.42 to $-0.07 \mathrm{mmol} / \mathrm{L})$. These subjects were also able to maintain a significant reduction in systolic blood pressure $(-3.2 \pm 1.2 \mathrm{mmHg} ; 95 \% \mathrm{CI}-5.5$ to $-0.8 \mathrm{mmHg})$ throughout the treatment period. ${ }^{69}$

\section{Impact on glucagon and other incretin-related effects}

Exenatide once weekly resulted in more glucagon suppression than exenatide twice daily. ${ }^{67}$ In the DURATION-1 study, glucagon levels changed by -18.0 (SE: 2.9 ) ng/L (from a baseline of $103(3 \cdot 1) \mathrm{ng} / \mathrm{L}$ ) and $-6 \cdot 4(2 \cdot 9) \mathrm{ng} / \mathrm{L}$ (from a baseline of $99 \cdot 0$ (3.0) ng/L) for exenatide once weekly and exenatide twice daily respectively $(P<0.05) .{ }^{67}$ The impact of exenatide once weekly on satiety and gastric emptying has not been examined. 


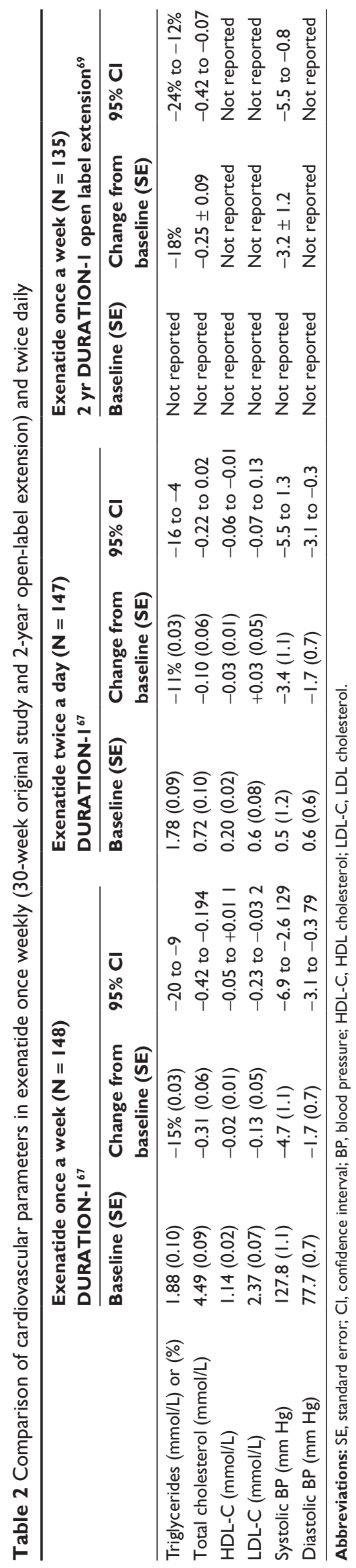

\section{Adverse events}

\section{Hypoglycemia}

There were no significant events of hypoglycemia reported with exenatide once weekly in the DURATION-1 study or its open-label extensions. ${ }^{67-69}$ In the Japanese study, patientreported hypoglycemia was reported in 2 patients. Both of these patients were on concomitant sulfonylurea therapy. ${ }^{66}$

In the earlier study by Kim et al patient-reported hypoglycemia was reported in $25 \%$ with exenatide once weekly $0.8 \mathrm{mg}$, of which only one was confirmed with a blood glucose level of $3.1 \mathrm{mmol} / \mathrm{L}$ and all were mild, and $0 \%$ in the 2.0 $\mathrm{mg}$ group; patients in the placebo arm had no hypoglycemia events. $^{64}$

\section{Other AEs}

The common AEs are summarized in Table 3. Nausea was the most commonly reported side effect. Other AEs included vomiting, diarrhea, injection-site pruritus, and bruising. Elevated blood amylase levels were reported in 2 patients in the exenatide $0.8 \mathrm{mg}$ once-weekly group, but these were not associated with any clinical symptoms of pancreatitis. Baseline to week 10 elevations in amylase levels did not reach significance in any of the groups, and no cases of pancreatitis were reported. There were no clinically relevant AEs relating to vital signs, ECG, or blood results. There were no withdrawals from the study due to AEs.

In the 2-year open-label extension of the DURATION-1 study, mild nausea diminished over time, occurring in only $8 \%$ of patients during the open-ended treatment period compared with $26.4 \%$ patients during the 30 -week study period. ${ }^{69}$

Overall, exenatide once weekly was well tolerated with no serious patient-reported AEs in any of the 3 published studies. Mild nausea and injection-site pruritus were commonly encountered. Incidences of hypoglycemia were mild. So far, no cases of acute pancreatitis have been reported in any of the studies.

\section{Anti-exenatide antibodies}

The development or presence of antibodies did not have any clinical effect on the incidence of hypoglycemia or change in $\mathrm{HbA}_{1 \mathrm{c}}$ in any of the available studies. ${ }^{64,66,67} \mathrm{Kim}$ et al reported that $67 \%$ of subjects receiving exenatide once weekly had anti-exenatide antibodies at week 15 , but no association could be found with safety or efficacy in individual patient profile. ${ }^{64}$ DURATION-1 reported that anti-exenatide antibody levels were higher with exenatide once a week compared with twicedaily exenatide $(P=0.0002)$; however, there were significant reductions in mean $\mathrm{HbA}_{1 \mathrm{c}}$ over 30 weeks in patients with 
Table 3 Most common AEs from the 3 published studies on exenatide once weekly

\begin{tabular}{|c|c|c|c|c|c|c|c|c|}
\hline \multirow[t]{2}{*}{ AE } & \multicolumn{3}{|l|}{ Kim et $\mathbf{a l}^{164}$} & \multicolumn{2}{|c|}{ Drucker et $\mathbf{a l}^{167}$} & \multicolumn{3}{|c|}{ Iwamoto et al ${ }^{66}$} \\
\hline & $\begin{array}{l}2.0 \mathrm{mg} \text { Ex } \\
\text { QW }\end{array}$ & $\begin{array}{l}0.8 \mathrm{mg} \text { Ex } \\
\text { QW }\end{array}$ & $\begin{array}{l}\text { Placebo } \\
\text { QW }\end{array}$ & $\begin{array}{l}2.0 \mathrm{mg} \text { Ex } \\
\text { QW }\end{array}$ & $\begin{array}{l}10 \mu \mathrm{g} \mathrm{Ex} \\
\text { BD }\end{array}$ & $\begin{array}{l}2.0 \mathrm{mg} \text { Ex } \\
\text { QW }\end{array}$ & $\begin{array}{l}0.8 \mathrm{mg} \text { Ex } \\
\text { QW }\end{array}$ & $\begin{array}{l}\text { Placebo } \\
\text { QW }\end{array}$ \\
\hline Nausea & $27 \%$ & $19 \%$ & $15 \%$ & $26.4 \%$ & $34.5 \%$ & 33.3 & 0 & 0 \\
\hline Vomiting & - & - & - & $10.8 \%$ & $18.6 \%$ & 11.1 & 0 & 10 \\
\hline Gastroenteritis/diarrhea & $13 \%$ & $19 \%$ & $0 \%$ & $13.5 \%$ & $13.1 \%$ & - & - & - \\
\hline Injection-site pruritus & - & - & - & $17.6 \%$ & $1.4 \%$ & 44.4 & 40 & 20 \\
\hline Injection site bruising/induration & $7 \%$ & $13 \%$ & $0 \%$ & $4.7 \%$ & $10.3 \%$ & 88.9 & 90 & 60 \\
\hline Constipation & - & - & - & $10.8 \%$ & $6.2 \%$ & - & - & - \\
\hline Upper respiratory tract infection & - & - & - & $8.1 \%$ & $17.2 \%$ & - & - & - \\
\hline
\end{tabular}

Abbreviations: $\mathrm{AE}$, adverse event; $\mathrm{Ex}$, exenatide; $\mathrm{QW}$, once weekly; $\mathrm{BD}$, twice daily.

negative, low titer (1/25 to $1 / 125)$, and high titer $(>1 / 625)$ antibodies in the exenatide once-weekly group compared with twice daily (Figure 2) ${ }^{67}$ Anti-exenatide antibodies were present in $60.0 \%(6 / 10)$ and $77.8 \%$ (7/9) of patients in the exenatide once-weekly $0.8 \mathrm{mg}$ and exenatide once-weekly $2.0 \mathrm{mg}$ groups, respectively, at any point during the Japanese study. But this did not have any clinical effect on hypoglycemia or $\mathrm{HbA}_{1 \mathrm{c}}$ change (data not available). ${ }^{66}$

\section{Ongoing clinical trials}

DURATION-2, a head-to-head comparative study of exenatide once weekly against sitagliptin or pioglitazone is a 26-week, double-blinded, phase 3, superiority study involving 491 patients whose diabetes was suboptimally controlled on metformin. Preliminary results were presented at the European Association for the Study of Diabetes annual meeting in 2008 and American Diabetes Association conference in

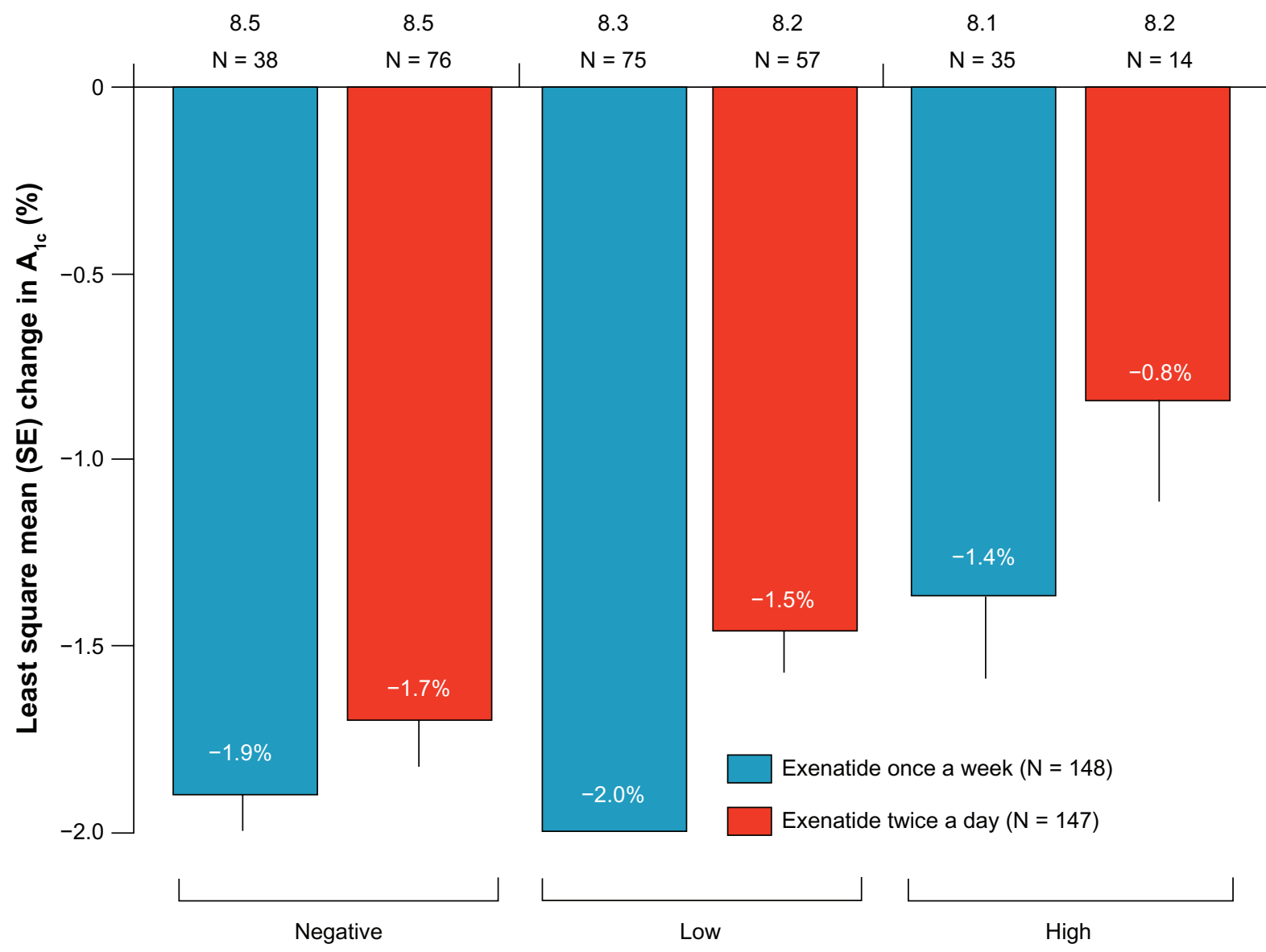

Figure 2 Intention-to-treat subanalysis ( $\mathrm{N}=295)$ of change in $\mathrm{HbA}_{\mathrm{lc}}$ (least square mean $(\mathrm{SE})$ by antibody status). Negative antibodies were not detectable in repeated analyses throughout the 30 weeks; low titer $(\leq 1 / 625)$ at any point during the 30 weeks; and high titer $(\geq 1 / 625)$ at any point during the 30 weeks; $\mathrm{HbA}$ reductions of $-1.4 \%$ were observed in patients treated once a week in the high titer group. Reprinted from Drucker DJ, Buse JB, Taylor K. DURATION-I: exenatide once weekly produces sustained glycemic control and weight loss over 52 weeks. The Lancet. 372:1240-1250, Copyright @ 2008, with permission from Elsevier. 
2009 , yet to be published. ${ }^{71,72} \mathrm{HbA}_{1 \mathrm{c}}$ reduction and weight loss was superior to the comparator arms; at 26 weeks the change in $\mathrm{HbA}_{1 \mathrm{c}}$ was $-1.55 \%,-0.92 \%$ and $-1.23 \%$ for exenatide once weekly, sitagliptin $100 \mathrm{mg}$ daily and pioglitazone 45 $\mathrm{mg}$ daily, respectively. Weight change was $-2.7 \mathrm{~kg},-0.9 \mathrm{~kg}$, and $+3.2 \mathrm{~kg}$ respectively. ${ }^{71,72}$

DURATION-3 was another phase 3, 26-week, openlabel, superiority study involving 467 patients with T2DM who were suboptimally controlled on metformin and/or a sulfonylurea, comparing exenatide once weekly with insulin glargine. The results are still awaited, but a press release reports a greater reduction in $\mathrm{HbA}_{1 \mathrm{c}}$, weight loss, and fewer hypoglycemic episodes in the exenatide once-weekly group compared with insulin glargine. ${ }^{73}$

DURATION-4 is currently in progress, comparing exenatide once weekly to metformin, sitagliptin, and pioglitazone; DURATION-5 is also ongoing, comparing exenatide once weekly to exenatide twice daily. Several other comparative trials are currently underway; details can be accessed from www.clinicaltrials.gov. ${ }^{74}$

\section{Patient considerations}

Diabetes imposes significantly on the patient's and carer's QOL, particularly considering the chronic and progressive nature of the disease, increasing treatment burden with time and multiple long-term complications and its attendant consequences, both financially and socially. ${ }^{5}$ Poor medication compliance is one of the major challenges for the success of treatment of conditions like diabetes and hypertension. ${ }^{75}$ Patient satisfaction and tolerability may have a decisive role in the use and choice of these new diabetes treatment options that will soon be available. ${ }^{76}$

The DURATION-1 study examined treatment satisfaction using Diabetes Treatment Satisfaction Questionnaire (DTSQ). The researchers found that patients treated with exenatide once weekly reported a significant increase in treatment satisfaction from baseline compared with exenatide twice daily, despite having similar compliance in the 2 groups (injections received/injections planned (98\%)). ${ }^{67}$

The treatment satisfaction and weight-related QOL in patients treated with exenatide once weekly was assessed in a randomized, multicenter, open-label study and involved 295 patients randomized to exenatide once weekly or exenatide twice daily for 30 weeks. ${ }^{76}$ At study-end, patients receiving exenatide twice daily were switched to exenatide once weekly for a further 22 weeks. DTSQ and Impact of Weight on Quality of Life - Lite (IWQOL-Lite) were assessed at baseline, 30 weeks, and 52 weeks. Both groups showed statistically significant improvements in DTSQ measures from baseline to week 30. At week 30, between-group differences from baseline in DTSQs total scores were not statistically significant $(5.17 \pm 0.54$ versus $3.97 \pm 0.53$; $P=0.09$ ), but treatment satisfaction did improve more in the exenatide once-weekly arm for perceived hypoglycemia frequency (from $1.86 \pm 0.15$ to $1.42 \pm 0.15 ; P=0.03$ ) and willingness to continue current treatment (from $1.43 \pm 0.13$ to $0.99 \pm 0.12 ; P=0.01){ }^{76}$

In the group who switched from exenatide twice daily to exenatide once-weekly at 30 weeks, DTSQ total score improved significantly $(1.16 \pm 6.1 ; P=0.037)$, as did treatment convenience $(0.42 \pm 1.6 ; P=0.003)$, treatment flexibility $(0.39 \pm 1.7 ; P=0.012)$ and satisfaction with continuing treatment $(0.24 \pm 1.3 ; P=0.048)$ by week 52 .

There were no statistically significant differences in weight-related QOL (IWQOL-Lite) between the 2 treatment arms at week 30. Treatment satisfaction and QOL improved significantly from weeks 30 to 52 in those who switched the regimen at week 30 , reporting further significant improvement in physical function $(2.13 \pm 11.5 ; P=0.04)$ and public distress $(5.04 \pm 11.2 ; P<0.001)$ domains. Patients who continued on once-weekly treatment improved significantly from week 30 to week 52 for public distress (6.96 \pm 13.2; $P<0.001){ }^{76}$

This study has several important highlights. Both exenatide twice daily and once weekly improved treatment satisfaction and weight-related QOL significantly. The fact that the effect was maintained over 52 weeks is encouraging and suggests that these effects may be durable and patients could benefit from the sustained clinical effects of the drug. There is some evidence that exenatide once-weekly therapy resulted in greater treatment satisfaction compared with exenatide twice daily, and patients who were on exenatide once weekly were more willing to continue treatment. This suggests that acceptance of exenatide once weekly may be more than for exenatide twice daily. This might be due to the ease of use and reduced frequency of injections. ${ }^{76}$ Furthermore, the efficacy of exenatide once weekly compared to exenatide twice daily and the reduction in the perceived frequency of hyperglycemia could also have contributed to the impact on treatment satisfaction. ${ }^{67}$

In the DURATION-2 study (described above), weightrelated QOL, psychological general wellbeing, diabetes treatment satisfaction, and general health status were assessed using the IWQOL-Lite, Psychological General Well-being (PGWB) index, DTSQ, and EQ-5D at baseline and week $26 .{ }^{77}$ The exenatide once-weekly group experienced significant improvement in physical function, self-esteem, sexual life, public distress, work, and IWQOL total score compared with pioglitazone; however, there were no significant differences 
between exenatide once weekly and sitagliptin. Overall treatment satisfaction improved significantly in the exenatide once-weekly group versus sitagliptin. Both exenatide once-weekly and sitagliptin groups experienced significant improvements in overall health status.

It is relevant to note that the recognised AEs of exenatide, both twice daily and once weekly, nausea and injection-site reactions did not deter patients from continuing with treatment, nor did it affect their QOL. ${ }^{76}$ This suggests that these issues may not be significant obstacles to improving patient acceptance of this new modality of treatment.

\section{Conclusion}

Exenatide once weekly is a new agent for the treatment of patients with T2DM and is currently going through phase 3 trials. Exenatide once weekly produce significant reduction in weight and glycemic parameters when compared with placebo or exenatide twice daily. These improvements were achieved with low risk of hypoglycemia and were sustainable up to 2 years in extension trials. Furthermore, exenatide once-weekly treatment has been shown to be associated with improvements in patient satisfaction and QOL, which might have a positive impact on patient adherence and compliance with treatment, which needs further testing in real-world situations. The results of the other phase 3 trials are awaited with interest.

\section{Disclosure}

Dr Abd Tahrani is a research training fellow supported by the National Institute for Health Research. The views expressed in this publication are those of the author(s) and not necessarily those of the NHS, the National Institute for Health Research or the Department of Health. AT has also won research grants from sanofi-aventis and Novo Nordisk UK Research Foundation. Prof. Anthony Barnett has received honoraria for lectures and advisory work and research funding from Servier, MSD, Novartis, Takeda, GlaxoSmithKline, BMS/Astra-Zeneca, Eli Lilly, Novo Nordisk, Roche and sanofi-aventis.

\section{References}

1. Mokdad AH, Ford ES, Bowman BA, et al. Prevalence of obesity, diabetes, and obesity-related health risk factors. J Am Med Assoc. 2003;289: 76-79.

2. IDF. The Diabetes Atlas. IDF [serial online] 2006.

3. de Groot M, Anderson R, Freedland KE, Clouse RE, Lustman PJ. Association of depression and diabetes complications: a meta-analysis. Psychosom Med. 2001;63:619-630.

4. Wanless D. Securing our future health: taking a long-term view [April 2002]. Available from: http://www.hm-treasury.gov.uk/consultations_and_ legislation/wanless/consult_wanless_final.cfm. Accessed Feb 12, 2010.
5. Jacobson AM. Impact of improved glycemic control on quality of life in patients with diabetes. Endocr Pract. 2004;10:502-508.

6. Facchini FS, Hua N, Abbasi F, Reaven GM. Insulin resistance as a predictor of age-related diseases. J Clin Endocrinol Metab. 2001;86: 3574-3578.

7. Stumvoll M, Goldstein BJ, van Haeften TW. Type 2 diabetes: principles of pathogenesis and therapy. Lancet. 2005;365:1333-1346.

8. Reaven GM. Role of insulin resistance in human disease. Diabetes. 1988;37:1595-1607.

9. Kahn SE, Hull RL, Utzschneider KM. Mechanisms linking obesity to insulin resistance and type 2 diabetes. Nature. 1988;444:840-846.

10. Kahn SE. The importance of [beta]-cell failure in the development and progression of type 2 diabetes. J Clin. Endocrinol Metab. 2001;86: 4047-4058.

11. Kahn SE. Quantification of the relationship between insulin sensitivity and B-cell function in human subjects. Evidence for a hyperbolic function. Diabetes. 1993;42:1663-1672.

12. Perley M, Kipnis DM. Plasma insulin responses to glucose and tolbutamide of normal weight and obese diabetic and nondiabetic subjects. Diabetes. 1966;15:867-874.

13. Polonsky KS, Given BD, van Cauter E. Twenty-four-hour profiles and patterns of insulin secretion in normal and obese subjects. J Clin Invest. 1988;81:442-448.

14. Burcelin R, Knauf C, Cani PD. Pancreatic alpha-cell dysfunction in diabetes. Diabetes Metab. 2008;34 (Suppl 2):S49-S55.

15. Salvatore T, Giugliano D. Pharmacokinetic-pharmacodynamic relationships of Acarbose. Clin Pharmacokinet. 1996;30:94-106.

16. Del PS, Bianchi C, Marchetti P. Beta-cell function and anti-diabetic pharmacotherapy. Diabetes Metab Res Rev. 2007;23:518-527.

17. Piya MK, Tahrani AA, Barnett AH. Liraglutide: a new option in the management of type 2 diabetes. Future Prescriber. 2008;9:6-12.

18. Redekkop WK, Koopmanschap MA, Stolk RP, Rutten GEH, Niessen LW. Health-related quality of life and treatment satisfaction in Dutch patients with type diabetes. Diabetes Care. 2002;25: 458-463.

19. UK Prospective Diabetes Study Group. Intensive blood-glucose control with sulphonylurea or insulin compared with conventional treatment and risk of complications in patients with type 2 diabetes (UKPDS 33). Lancet. 1998;352:837-853.

20. Cramer JA. A systematic review of adherence with medications for diabetes. Diabetes Care. 2004;27:1218-1224.

21. Glasgow RE. Compliance to diabetes regimens: conceptualization, complexity, and determinants. In: Cramer JA, Spilker B, editors. Patient Compliance in Medical Practice and Clinical Trials. New York: Raven Press; 1991:209-224.

22. Pugh MJ, Anderson J, Pogach LM, Berlowitz DR. Differential adoption of pharmacotherapy recommendations for type 2 diabetes by generalists and specialists. Med Care Res Rev. 2003;60:178-200.

23. Tahrani AA, Piya MK, Kennedy A, Barnett AH. Glycaemic control in type 2 diabetes: targets and new therapies. Pharmacol Ther. 2010 Feb; 125(2):328-361.

24. Palalau AI, Tahrani AA, Piya MK, Barnett AH. DPP-4 inhibitors in clinical practice. Postgrad Med. 2009;121(6):70-100.

25. Tahrani AA, Piya MK, Barnett AH. Saxagliptin: a new DPP-4 inhibitor for the treatment of type 2 diabetes mellitus. Adv Ther. 2009; 26:249-262.

26. Peters A. Incretin-based therapies: review of current clinical trial data. Am J Med. 2010;123 (Suppl 3):S28-S37.

27. Tahrani AA, Piya MK, Barnett AH. Drug evaluation: vildagliptinmetformin single-tablet combination. Adv Ther. 2009 Feb;26(2): $138-154$.

28. Ahren B. Gut peptides and type 2 diabetes mellitus treatment. Curr Diab Rep. 2003;3:365-372.

29. Elrick H, Stimmler L, Hlad CJ Jr, Rai Y. Plasma insulin response to oral and intravenous glucose administration. J Clin Endocrinol Metab. 1964;24:1076-1082. 
30. Nauck MA, Homberger E, Siegel EG, et al. Incretin effects of increasing glucose loads in man calculated from venous insulin and C-peptide responses. J Clin Endocrinol Metab. 1986;63:492-498.

31. Brown JC, Dryburgh JR. A gastric inhibitory polypeptide. II. The complete amino acid sequence. Can J Biochem. 1971;49:867-872.

32. Dupre J, Ross SA, Watson D, Brown JC. Stimulation of insulin secretion by gastric inhibitory polypeptide in man. J Clin Endocrinol Metab. 1973;37:826-828.

33. Baggio LL, Drucker DJ. Biology of incretins: GLP-1 and GIP. Gastroenterology. 2007;132:2131-2157.

34. Kim W, Egan JM. The role of incretins in glucose homeostasis and diabetes treatment. Pharmacol Rev. 2008;60(4):470-512.

35. Drucker DJ, Philippe J, Mojsov S, Chick WL, Habener JF. Glucagonlike peptide I stimulates insulin gene expression and increases cyclic AMP levels in a rat islet cell line. Proc Natl Acad Sci U S A. 1987;84: 3434-3438.

36. Nauck MA, Homberger E, Siegel EG, et al. Incretin effects of increasing glucose loads in man calculated from venous insulin and C-peptide responses. J Clin Endocrinol Metab. 1986;63:492-498.

37. Ahren B. Gut peptides and type 2 diabetes mellitus treatment. Curr Diab Rep. 2003;3:365-372.

38. Drucker DJ. Glucagon-like peptide-1 and the islet beta-cell: augmentation of cell proliferation and inhibition of apoptosis. Endocrinology. 2003;144:5145-5148.

39. Toft-Nielsen MB, Damholt MB, Madsbad S, et al. Determinants of the impaired secretion of glucagon-like peptide- 1 in type 2 diabetic patients. J Clin Endocrinol Metab. 2001;86:3717-3723.

40. Nauck MA, Kleine N, Orskov C, Holst JJ, Willms B, Creutzfeldt W. Normalization of fasting hyperglycaemia by exogenous glucagon-like peptide 1 (7-36 amide) in type 2 (non-insulin-dependent) diabetic patients. Diabetologia. 1993;36:741-744.

41. Gutniak MK, Linde B, Holst JJ, Efendic S. Subcutaneous injection of the incretin hormone glucagon-like peptide 1 abolishes postprandial glycemia in NIDDM. Diabetes Care. 1994;17:1039-1044.

42. Deacon CF, Johnsen AH, Holst JJ. Degradation of glucagon-like peptide-1 by human plasma in vitro yields an $\mathrm{N}$-terminally truncated peptide that is a major endogenous metabolite in vivo. JClin Endocrinol Metab. 1995;80:952-957.

43. Mentlein R. Dipeptidyl-peptidase IV (CD26) - role in the inactivation of regulatory peptides. Regul Pept. 1999;85:9-24.

44. Barnett A. Exenatide. Expert Opin Pharmacother. 2007;8: 2593-2608.

45. BYETTA prescribing information [article on the Internet]. Available from: http://pi.lilly.com/us/byetta-pi.pdf. Accessed Feb 16, 2010.

46. Triplitt C, DeFronzo RA. Exenatide: first-in-class incretin mimetic for the treatment of type 2 diabetes mellitus. Expert Rev Endocrinol Metab. 2006;1:329-341.

47. Kolterman OG, Kim DD, Shen L, et al. Pharmacokinetics, pharmacodynamics, and safety of exenatide in patients with type 2 diabetes mellitus. Am J Health Syst Pharm. 2005;62:173-181.

48. DeFronzo RA, Ratner RE, Han J, Kim DD, Fineman MS, Baron AD. Effects of exenatide (exendin-4) on glycemic control and weight over 30 weeks in metformin-treated patients with type 2 diabetes. Diabetes Care. 2005;28:1092-1100.

49. Barnett AH, Burger J, Johns D, et al. Tolerability and efficacy of exenatide and titrated insulin glargine in adult patients with type 2 diabetes previously uncontrolled with metformin or a sulfonyulurea: a multinational, randomized, open-label, two-period, crossover noninferiority trial. Clin Ther. 2007;29(11):2333-2348.

50. Poon T, Nelson P, Shen L, et al. Exenatide improves glycemic control and reduces body weight in subjects with type 2 diabetes: a doseranging study. Diabetes Technol Ther. 2005;7:467-477.

51. Kolterman OG, Buse JB, Fineman MS, et al. Synthetic Exendin-4 (exenatide) significantly reduces post-prandial and fasting plasma glucose in subjects with Type 2 diabetes. $J$ Clin Endocrinol Metab. 2007;88(7):3082-3089.
52. Edwards CM, Stanley SA, Davis R, et al. Exendin-4 reduces fasting and postprandial glucose and decreases energy intake in healthy volunteers. Am J Physiol Endocrinol Metab. 2001 Jul;281:E155-E161.

53. Toft-Nielsen MB, Madsbad S, Holst JJ. Continuous subcutaneous infusion of glucagon-like peptide 1 lowers plasma glucose and reduces appetite in type 2 diabetic patients. Diabetes Care. 1999 Jul; 22(7):1137-1143.

54. Ratner RE, Maggs D, Nielsen LL, et al. Long-term effects of exenatide therapy over 82 weeks on glycaemic control and weight in over-weight metformin-treated patients with type 2 diabetes mellitus. Diabetes Obes Metab. 2006;8(4):419-428.

55. Buse JB, Henry RR, Han J, et al. Effects of exenatide (exendin-4) on glycemic control over 30 weeks in sulfonylurea-treated patients with type 2 diabetes. Diabetes Care. 2004;27:2628-2635.

56. Kendall DM, Riddle MC, Rosenstock J, et al. Effects of exenatide (exendin-4) on glycemic control over 30 weeks in patients with type 2 diabetes treated with metformin and a sulfonylurea. Diabetes Care. 2005; 28:1083-1091.

57. Riddle MC, Henry RR, Poon TH, et al. Exenatide elicits sustained glycaemic control and progressive reduction of body weight in patients with type 2 diabetes inadequately controlled by sulphonylureas with or without metformin. Diabetes Metab Res Rev. 2006;22: 483-491.

58. Klonoff DC, Buse JB, Nielsen LL, et al. Exenatide effects on diabetes, obesity, cardiovascular risk factors and hepatic biomarkers in patients with type 2 diabetes treated for at least 3 years. Curr Med Res Opin. 2008; $24: 275-286$

59. Buse JB, Klonoff DC, Nielsen LL, et al. Metabolic effects of two years of exenatide treatment on diabetes, obesity, and hepatic biomarkers in patients with type 2 diabetes: an interim analysis of data from the openlabel, uncontrolled extension of three double-blind, placebo controlled trials. Clin Ther. 2007;29:139-153.

60. FDA prescribing information for exenatide. Available from: http:// www.accessdata.fda.gov/drugsatfda_docs/label/2008/021773s012lbl. pdf. Accessed Mar 18, 2010.

61. Monami M, Marchionni N, Mannucci E. Glucagon-like peptide-1 receptor agonists in type 2 diabetes: a meta-analysis of randomized clinical trials. Eur J Endocrinol. 2009;160:909-917.

62. Dore DD, Seeger JD, Arnold CK. Use of a claims-based active drug safety surveillance system to assess the risk of acute pancreatitis with exenatide or sitagliptin compared to metformin or glyburide. Curr Med Res Opin. 2009;25:1019-1027.

63. Tracy MA, Ward KL, Firouzabadian L, et al. Factors affecting the degradation rate of poly(lactide-co-glycolide) microspheres in vivo and in vitro. Biomaterials. 1999;20:1057-1062.

64. Kim D, MacConell L, Zhuang D, et al. Effects of once-weekly dosing of a long-acting release formulation of exenatide on glucose control and body weight in subjects with type 2 diabetes. Diabetes Care. 2007; 30:1487-1493.

65. Taylor K, Kim D, Nielsen LL, Aisporna M, Baron AD, Fineman MS. Day-long subcutaneous infusion of exenatide lowers glycemia in patients with type 2 diabetes. Horm Metab Res. 2005;37:627-632.

66. Iwamoto K, Nasu R, Yamamura A, et al. Safety, tolerability, pharmacokinetics, and pharmacodynamics of exenatide once weekly in Japanese patients with type 2 diabetes. Endocr J. 2009;56(8): 951-962.

67. Drucker DJ, Buse JB, Taylor K, et al. Exenatide once weekly versus twice daily for the treatment of type 2 diabetes: a randomised, openlabel, non-inferiority study. Lancet. 2008;372:1240-1250.

68. Buse JB, Drucker DJ, Taylor K, et al. DURATION-1: exenatide once weekly produces sustained glycemic control and weight loss over 52 weeks. Diabetes Care. 2010;33(6):1255-1261.

69. Trautmann M, Wilhelm K, Taylor K, Kim T, Zhuang D, Porter L. Exenatide once-weekly treatment elicits sustained glycaemic control and weight loss over 2 years. Diabetologia. 2009; 52 (Suppl 1):S286. 
70. Kadowaki T, Namba M, Yamamura A, Sowa H, Wolka AM, Brodows RG. Exenatide exhibits dose-dependent effects on glycemic control over 12 weeks in Japanese patients with suboptimally controlled type 2diabetes. Endocr J. 2009;56:415-424.

71. Wysham C, Bergenstal R, Yan P, MacConell L, Malloy J, Porter L. DURATION-2: exenatide once weekly demonstrated superior glycaemic control and weight reduction compared to sitagliptin or pioglitazone after 26 weeks of treatment. Diabetologia. 2009;52 (Suppl 1):S290.

72. Bergenstal R, Wysham C, Yan P, Macconell L, Malloy J, Porter L. DURATION-2: exenatide once weekly demonstrated superior glycemic control and weight reduction compared to sitagliptin or pioglitazone after 26 weeks of treatment. Presented at ADA 2009. San Diego, CA: 2009.

73. Press Release. Amylin, Lilly and Alkermes companies announce exenatide once weekly provided superior glucose control compared to Lantus in head-to-head DURATION-3 study. San Diego, CA: Amylin Pharmaceuticals; 2009. Available from: http://files.shareholder.com/ downloads/LLY/0x0x307776/675c0e3a-b736-4a08-a30c-bab4ec187b39/ LLY_News_2009_7_20_Product.pdf. Accessed February 27, 2010.
74. Current trials involving exenatide LAR. Available from: http:// clinicaltrials.gov| http://clinicaltrials.gov/. Accessed Mar 18, 2010.

75. DiMatteo MR, Giordani PJ, Lepper HS, Groghan TW. Patient adherence and medical outcomes: a meta-analysis. Med Care. 2002;40: 794-811.

76. Best JH, Boye KS, Rubin RR, Cao D, Kim TH, Peyrot M. Improved treatment satisfaction and weight-related quality of life with exenatide once weekly or twice daily. Diabet Med. 2009;26(7): $722-728$.

77. Best JH, Yan P, Malloy J. DURATION 2: weight-related quality of life, psychological well-being, and satisfaction with exenatide once weekly compared to sitagliptin or piaglitazone after 26 weeks of treatment. Diabetologia. 2009;52 (Suppl 1):S292.

\section{Publish your work in this journal}

Patient Preference and Adherence is an international, peer-reviewed, open access journal focusing on the growing importance of patient preference and adherence throughout the therapeutic continuum. Patient satisfaction, acceptability, quality of life, compliance, persistence and their role in developing new therapeutic modalities and compounds to optimize clinical outcomes for existing disease states are major areas of interest. This journal has been accepted for indexing on PubMed Central. The manuscript management system is completely online and includes a very quick and fair peer-review system. Visit http://www.dovepress.com/ testimonials.php to read real quotes from published authors. 